perhaps a couple of thousand feet below, the top of the ridge which connects all the Ruwenzori snow-peaks. Assuming this ridge to be at something like 17,000 feet in altitude, the high peaks of Ruwenzori would again rise two or three thousand feet higher, and thus the supreme altitude of 20,000 feet of the highest point of Ruwenzori which has been predicted by Major Gibbons, Sir Harry Johnston, Mr. Wylde and others is more likely to be nearer the ultimate truth than Mr. Moore's assertion that the greatest height of Ruwenzori is probably not more than 17,000 feet in total altitude.

Mr. Moore makes some very interesting remarks on the causes which probably led to the formation of the park like scenery so characteristic of tropical Africa. On recently formed alluvial flats those strange and hideous attention of all who are interested in tropical Africa His pessimistic description, however, of the future prospects for European trade with these countries can be easily corrected by a glance at the statistics issued by the African Protectorates. Countries the trade of which has risen in a few years from an annual value of 30,000 . to a quarter of a million, while their local revenue has grown from nothing a year to $50,000 \%$. or $60,000 l$., cannot be such hopeless investments for European commerce and enterprise as $\mathrm{Mr}$. Moore would have us believe.

Mr. Moore was accompanied on his journey by a surveyor, Mr. Malcolm Ferguson, whose surveys are certainly one of the valuable results of the expedition. If $\mathrm{Mr}$. Ferguson is to be regarded as more accurate than his predecessors his work will result in the shifting of the

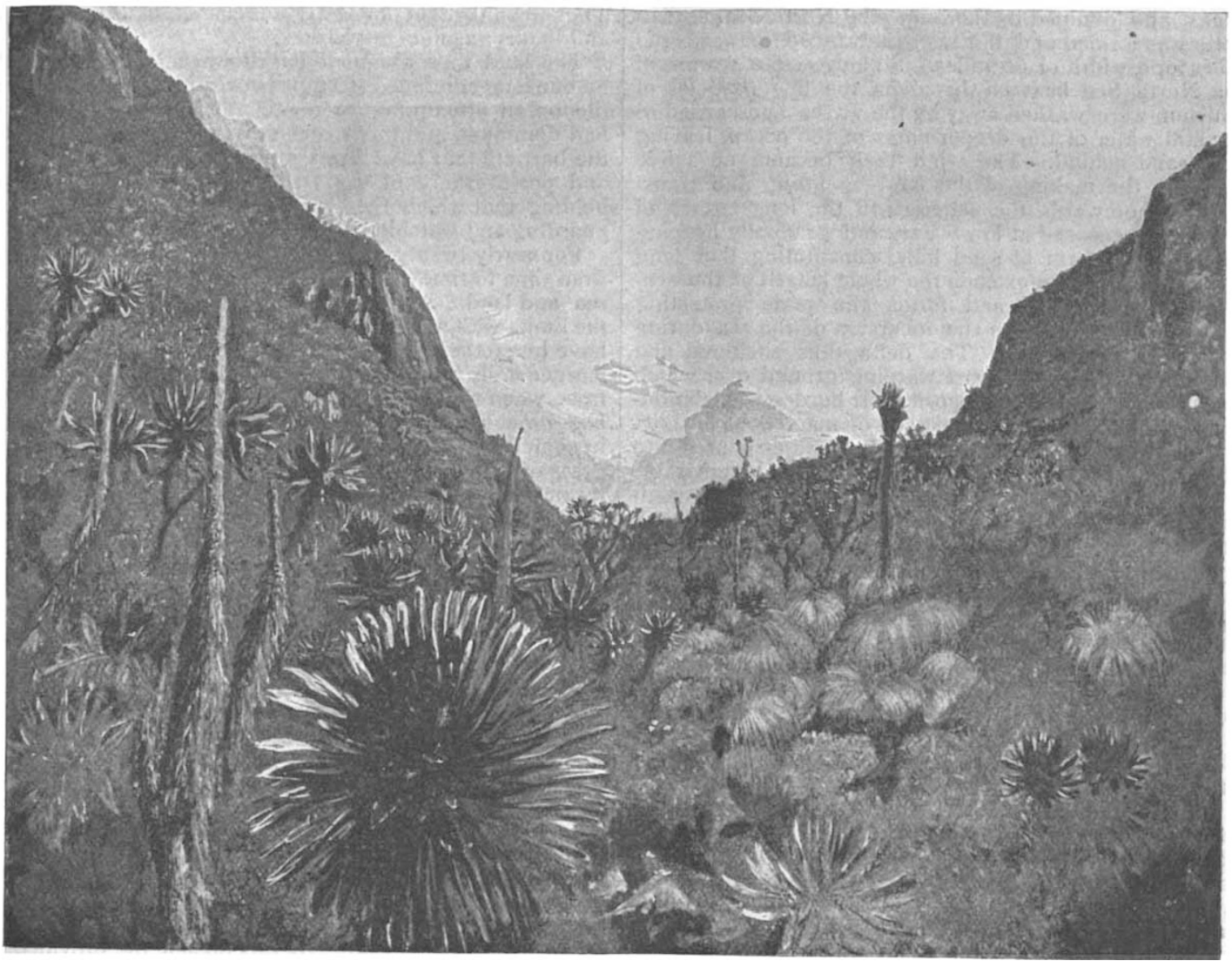

F1G. 2.-The Northern Snow Ridge of Ingomwimbi from a point about $r 2,500$ feet.

fleshy euphorbias commence to grow on what is, to begin with, a shadeless, sandy wilderness, where all seedlings which might form forest trees are burnt up and withered by the scorching sun. The euphorbia, however, resists the sun's rays, being distinctly a plant of the desert. As its candelabra branches increase in numbers and spread out to the right and left they create shade, while the fallen branches decay and form vegetable soil. Under this protection and by this nourishment seedlings of palms and forest trees survive and flourish. When they have got a good hold on the soil the original euphorbia is long since dead or hidden, and the park-like clumps of handsome trees have become a permanent feature over what was once a wind-swept, sun-scorched, barren plain.

We strongly recommend Mr. Moore's book to the NO. [682, VOL. 65$]$ northern end of Lake Tanganyika nearly half a degree further to the west, while he will also have supplied us with the first approximately correct delineation of Lake Albert Edward.

\section{THE RECLAMATION OF THE ZUIDERZEE.}

$\mathrm{I}$ a recent consular report from the Netherlands, issued by the Foreign Office, reference is made to a Bill which was introduced in the Second Chamber of the States General, for the purpose of obtaining authority to carry out the works required for the first portion of a scheme for reclaiming 800 square miles of land from the Zuiderzee, and for raising the necessary funds, estimated at eight million pounds, the cost of the entire scheme 
being put at $15 \frac{3}{4}$ millions. A translation of the Bill and explanatory memorandum of the Minister of the Waterstaat are also given.

This scheme for adding land to the seven provinces of the United Netherlands is only a continuation of those bloodless conquests which Holland has been carrying on for the last twenty centuries, by which, little by little, the cultivated area of the country has been enlarged without annexation, or encroachment on neighbouring countries.

Holland affords the most remarkable example of the operations of Nature in that process of destruction and reconstruction of the earth on which we live that is always in process. The land is almost entirely conposed of the off scourings of Swiss, German and French territory washed off the land by the rain, transported several hundred miles by the rivers Rhine, Scheldt and Maas, and dumped by them into the North Sea, until a delta was formed and the shore advanced seaward 130 miles for a width of 60 miles. So long as the storms of the North Sea beat on this delta the fine particles of alluvium were washed away by the waves and carried to the still water of the deeper parts of the ocean, leaving only sand behind. The wind then became an active agent in the making of the land by lifting and transporting shorewards the material off the long stretch of bare sands exposed at low water, and gradually heaping it up in the form of sand hills, constituting that long line of dunes which extends the whole length of the seaboard for 230 miles and forms the main protecting barrier of the land from the incursion of the sea during storms and high tides. The delta thus sheltered and protected became one vast warping ground over which the rivers continued to deposit their burden of rich alluvium, gradually building up a soil of marvellous fertility.

Through the surface thus raised the water poured into the delta found its way to sea through innumerable channels which finally concentrated in three main openings through the dunes. The surface thus became an amphibious country, half land and half water, divided by numerous channels into islands. At the time when historical records begin some of these islands had risen above the level of the tides, and the country consisted of large alluvial plains the greater part below mean sea level, large meres or lakes from I 5 to 20 feet deep, and deep winding channels, the whole bordered by the higher plains on the south and east composed of sand and drift.

At this epoch man stepped in to gather the fruits of that which the contending forces of rain and rivers, storms and tempest, wind and tides had produced.

The Roman records afford some outline of the condition of Holland at this time, from which it is known that early in the Christian era the higher diluvial lands, dunes and heaths were occupied by the Batavians, who gained a precarious living by hunting, fishing, and pasturing cattle in summer on the alluvial islands.

Whether the first embanking and reclamation was done by the Batavians or by the Romans is uncertain, but records exist showing that the latter, recognising the value of these rich lands for corn growing, commenced a system of reclamation by making more direct channels for the flood waters, and embanking the lands.

This system of reclaiming the land of the delta has gone on persistently ever since. At first only the higher lands were embanked, but as population increased the aid of science was invoked, and mechanical agency was applied to the raising of the water from the shallower meres and lakes, the motive power being the wind. For four and a half centuries the fens and morasses, lakes and old river beds which had been converted into cultivated land were kept dry by the aid of innumerable windmills studded all over the country, some of the deeper polders requiring three engines, at different levels, to raise and discharge the water. About sixty years ago steam power was added to that of the wind, being first used for the drainage of Lake Harlem, by which 45,000 acres of rich land were recovered and a new province of 10,000 inhabitants added to the country. "What was once a lake from $I_{5}$ to 20 feet deep is now the great market garden of Amsterdam. "And so by the skill and genius of man there was thus driven from the bosom of the country a most dangerous enemy, and a province was conquered without tears and without bloodshed, the engineer taking the place of the general and the navvy that of the soldier."

Such is the physical history of the provinces of Holland known as the United Netherlands, which has a population of nearly five millions and covers an area of 12,738 square miles, of which about two-thirds consist of reclaimed lands, intersected by a system of main drains and navigable canals extending to a length of 2050 miles. The annual budget for the maintenance of these drains and banks amounts to 500,000 .

The land thus obtained has, however, only been held by one long-continued struggle between man and Nature the ocean attempting to regain the land over which it had dominion, and the rivers striving to break through the barriers that have been imposed on them, the skill and perseverance of the Dutchmen being exercised in holding that which they had gained by the most careful guarding and watching.

For nearly twenty centuries the fight has been going on, from time to time the land being attacked both from the sea and land. At different periods the rivers, resenting the limits within which their waters have been restrained, have burst their bounds and flooded the country. This has generally happened after the breaking up of some great frost, when the water, flowing down in enormous volumes, has brought with it broken ice-drifts which, blocking in some bend or other obstruction, have stopped the progress of the flood. When this occurs the water finds relief by running over the top of the banks or breaking through them, covering thousands of acres and inundating villages and homesteads. Thus in the fifteenth century the Rhine burst its banks and flooded 100,00 acres and seventy villages. In another great flood nearly the whole of Holland was inundated and 400 ,ooo lives were lost, the country being so depopulated owing to this vast loss of life that the damage done could not be made good, or the prosperity of the country restored, for many years.

Even more disastrous than the land floods have been the breaches made in the sand-hills and sea-dykes by abnormal high tides, due to gales lasting over several days, driving the water upon the shore. It was owing to one of these great storms, at the latter end of the thirteenth century, which lasted for several days, that the water of the North Sea was raised to an unprecedented height and driven by the north-west gale on the sandbanks which protected the north coast, breaking through these in several places and inundating an enormous tract of country lying behind. By this breach the province of Friesland was separated from that of North Holland, and the water, uniting with Lake Flevo, formed the Zuiderzee, a vast inland salt-water sea 80 miles long and in places 30 miles wide. Remains of the original coast-line exist in the islands of Texel, Vlieland, Tor Schelling and Ameland. In the Zee the higher parts of the inundated land are now marked by the islands of Wieringen, Schakland, Marken and Urk, the latter of which is so little above the level of the sea that the greater part of it is covered with water whenever extraordinarily high tides occur, the houses and church standing on mounds slightly elevated above the rest of the island. Numerous villages, with their churches and homesteads, which once contained a numerous population, now lie buried beneath the waters of the Zuiderzee, and it is stated that 80,000 of the inhabitants lost their lives.

For more than six centuries the area then drowned has remained an inland sea, on which a numerous fishing

NO. I 682 , VOL. 65 ] 
population gains its living, the plough and the waggon having given place to the net and the boat.

The reclamation of Lake Harlem having demonstrated the great advantages to be gained by such works, several schemes were subsequently brought forward for reclaiming the Zuiderzee and regaining what was thus stolen by the sea, the most extensive of these plans proposing the joining together of the islands which were left standing, and filling the gaps between them by embankments.

At last, in I894, a Commission of twenty-seven members was appointed by the Government to make a thorough investigation of the subject, the commissioners being selected for their special capabilities for determining as to the practicability of the reclamation from an engineering point of view, and as to the cost ; as to the adaptability of the land for agricultural purposes, and its value when reclaimed; as to the proper way of dealing with the interests of the fishermen who would be displaced; and generally the advantages that would occur to the State. This Commission reported in 1892 , and recently a Bill was brought before the Dutch States General for carrying into effect the recommendations of the commissioners. Owing to a change in the Ministry the Bill lapsed before it had passed through the necessary stages, but there is no doubt that it will be revived in due course by the new Ministry.

The idea of entirely reclaiming the whole of the Zuiderzee by uniting the islands has been abandoned as commercially. impracticable, and a modified scheme adopted for only enclosing the inner portion by an embankment 18 miles in length, extending from the North Holland coast near the island of Wieringen to the Friesland coast near Piaam. The top of this embankment will require to be 18 feet above mean high water, and it is proposed to construct in it two locks and six outfall sluices, giving a total waterway of 984 feet for the discharge of the water from the River Ysell. One of the locks is to be of sufficient size for sea-going craft, which will thus be able to get to Amsterdam through the locks at Schellingwoude and to other parts of Holland along the various canals that now have communication with the Zuiderzee. On the top will run a road and railway. The estimated cost of this bank is $3,000,000 l$. When the bank is completed it is proposed to reclaim two large areas of land on the west side which are now covered by, water, containing together I $3 \mathrm{I}, 45^{\circ}$ acres, of which I I 5,000 acres will be available for cultivation, the remainder being occupied by roads, drainage canals and banks. For the drainage of these reclaimed polders eight steam pumps will be required, of an aggregate capacity of $433^{\circ}$ horse-power.

Subsequently it is intended to reclaim two further tracts containing 365,288 acres, but this reclamation was not included in the Bill now under consideration. When this is done there will remain a large area of water, practically the site of Lake Flevo, covering 560 square miles. It is considered that the depth of the water in this lake is too great for profitable reclamation. The cost of enclosing the two tracts of land and providing the necessary pumping machinery is estimated at $2,962,500 \mathrm{l}$. For the interests of the fishery $375,000 \mathrm{l}$. is allocated ; for military defences, 666,0ool. ; for deepening the approaches to the harbours and other works in the interests of the navigation, 7I7,000l., making, with the cost of the bank, a total estimated cost of $7,720,500 l$. The enclosure of the eastern polders, containing 365,288 acres of cultivatable land, is estimated at 7,862,500l., making a grand total of $15,583,000 l$.

The enclosing dyke is reckoned to occupy nine years the reclamation of the western polders would be completed at the end of fourteen years, and it would take thirty-three years before the whole reclamation could be completed.

It is proposed that the cost of the works, amounting NO. I682, VOL. 65$]$ to $7,720,500 l$., shall be repaid by annual instalments spread over sixty years, requiring an annual charge of $166,667 \%$. The renting value of the reclaimed land is estimated at $230,000 l$. a year, showing an annual financial gain of $63,333 l$.

It is considered that, even if no financial gain should ensue, the scheme is one that will be of eminent advantage in the increase in the general prosperity:-by creating a better condition of the Waterstaat over a considerable portion of the country, and in effecting a large saving in the cost at present incurred in pumping; and in the maintenance of the sea banks, the length of which will be reduced from 198 to 25 miles; by the establishment of direct communication by road and railway along the new bank between North Holland and Friesland, which will shorten the distance between Leuwarden and Amsterdam 35 miles; and, above all, by the economic advantages that will be derived from the cultivation of a very extensive tract of land, and the employment that will be given to a very large population.

W. H. WHEELER.

\section{SMALL-POX IN LONDON.}

CHE statistical committee of the Metropolitan Asylums Board has recently presented an interesting report upon the cases of small-pox which have been treated by the Board during the year rgor. This report enables us to trace the growth of the present epidemic, and, so far as it goes, dealing with IOI7 cases of smallpox, teaches us some very useful lessons upon a subject at the present time of the most profound interest, viz., the efficacy of vaccination as a protective measure.

It appears that in the early part of last year, in fact up to August, London was unusually free from small-pox, only slightly more than a dozen cases having occurred. From August 22 and on, however, the disease appeared to have obtained a strong hold in the parishes of St. Marylebone and St. Pancras. Subsequently cases occurred in every one of the thirty-one poor-law parishes and unions comprising the Metropolitan Asylum District. The average weekly admissions were as follows:-In August, 35.5, September, 3775 ; October, 39.75; November, I I 3.6 ; December I to 28,1645 ; December 28 to January 4 , $242^{\circ} \mathrm{O}$.

With regard to gross mortality, this is given at 2428 per cent. It must, however, be borne in mind that in arriving at this figure many cases of recent admissions have been included because they have already been completed by death, whereas the contemporary cases, which will probably nearly all recover ultimately, cannot be included until completed by discharge. The result is that the rate of mortality above must be admitted to be undoubtedly higher than it will be when all the cases have been completed and the final rate ascertained.

For the purpose of estimating the effect of vaccination upon the cases which have died or recovered during the year, these were divided into three classes: (I) cases with visible cicatrices, (2) doubtful cases, (3) unvaccinated cases. The total mortality rate per cent. of vaccinated cases was I $4.2 \mathrm{I}$; of doubtful cases $65^{\circ} 08$; of unvaccinated cases $5^{\circ} 52$. It strikes one at first as odd that the mortality of the doubtful cases was ten per cent. higher than that of the admittedly unvaccinated. By definition it, however, appears that the doubtful cases most probably consisted of practically unvaccinated cases, and were very few in number. Perhaps one of the most marked features in these statistics is the protection from smallpox afforded by successful infantile vaccination. Under ten years of age only twelve vaccinated cases are recorded and no death. Infantile vaccination, further, seemed greatly to diminish the rate of mortality from the disease even up to forty, although there was a very rapid 